\title{
Congenital ataxia due to cerebellar malformation presenting with unilateral hypoplasia
}

Ataxia congênita devido à malformação cerebelar com hipoplasia unilateral

Paulo Victor Sgobbi de Souza, Wladimir Bocca Vieira de Rezende Pinto, José Luiz Pedroso, Orlando Graziani Povoas Barsottini

A ten-year-old girl presented with an eight-year history of non-progressive gait instability, frequent falls, and delayed learning skills since the first year. There was no consanguinity. Neurological examination showed gait ataxia, cognitive impairment, and horizontal gaze palsy. Renal and hepatic tests were normal. Brain Magnetic Resonance Imaging (MRI) showed left cerebellar hypoplasia (Figure).

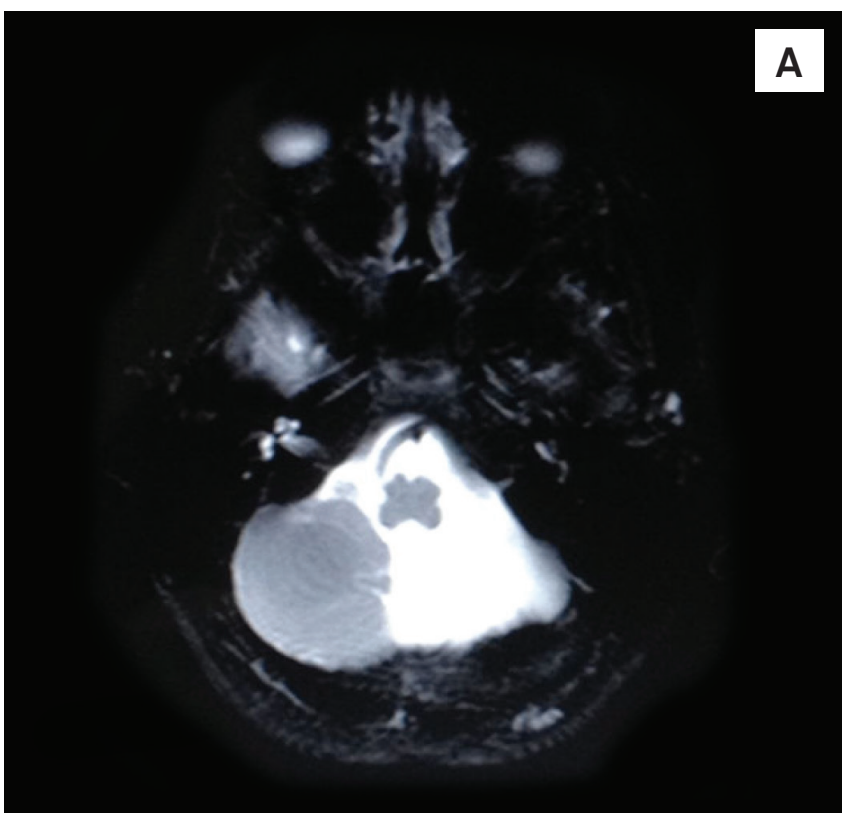

Cerebellar malformations comprise a heterogeneous group of neurological conditions and include Joubert syndrome, Dandy-Walker, cerebellar hypoplasia, cerebellar agenesis, posterior fossa cysts, and others. ${ }^{1}$ Unilateral cerebellar hypoplasia is a rare syndrome encompassing a spectrum that ranges from complete aplasia to asymmetric hypoplasia. Some causes may include: prenatal cerebellar insult (such as hemorrhage), PHACES syndrome or other genetic etiologies. ${ }^{2}$

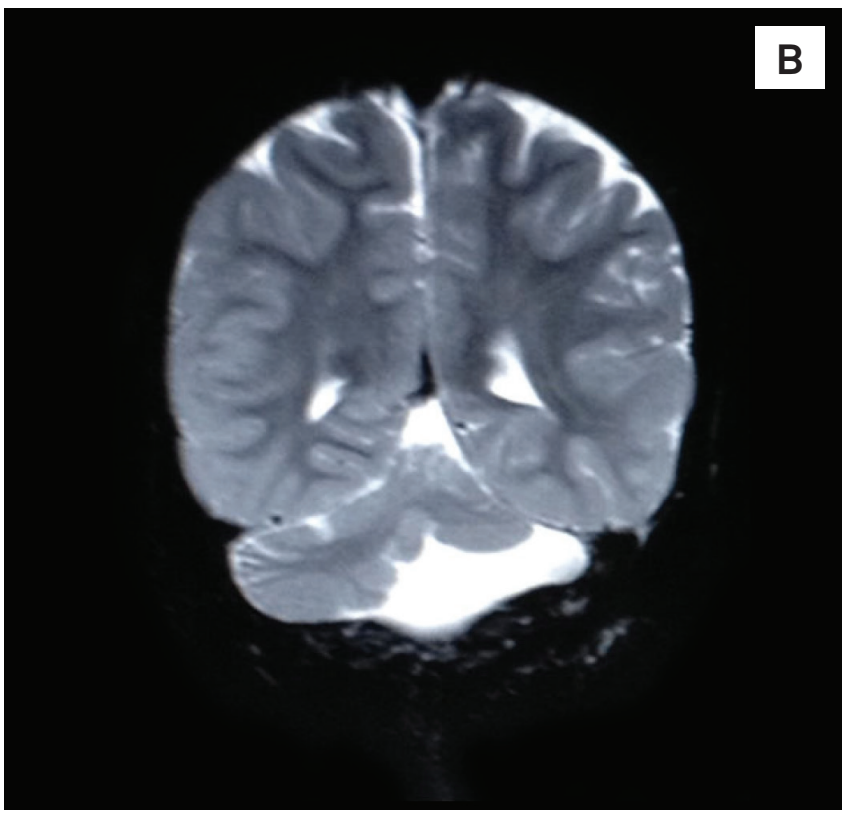

Figure. (A) Axial T2-weighted brain MRI showing cerebellar hypoplasia of the left hemisphere and cerebellar vermis; (B) Coronal T2-weighted brain MRI, disclosing hypoplasia of the inferior left cerebellar hemisphere.

\section{References}

Steinlin M. Non-progressive congenital ataxias. Brain Dev 2. 1998;20:199-208.
Poretti A, Limperopoulos C, Roulet-Perez E, et al. Outcome of severe unilateral cerebellar hypoplasia. Dev Med Child Neurol 2010;52:718-724. 